\title{
Evaluation of Oxford Progressive English Text Book: A Qualitative Study
}

\author{
* Abdul Ali, PhD Scholar (Corresponding Author) \\ ** Amara Javed, Assistant Professor \\ *** Dr. Ghulam Murtaza, Associate Professor
}

\begin{abstract}
Textbook evaluation is considered an important factor in the field of education from the aspect of teachers and learners. The current examination aims to evaluate the Oxford Progressive English textbook for 8th class. The current study aims to probe strong and weak points in the given coursebook. Besides, whether the textbook should be accepted or rejected will also be explored in this study. As for research methodology, the nature of the present research is of descriptive qualitative. The sample for the evaluation is the Oxford Progressive English text for the 8th class Checklist method and an impressionistic method "as an instrument will be used for evaluating the ELT material. The following "Checklist" was used to evaluate the textbook. Sheldon's checklist has been used as an instrument of the research. The data has been collected from the textbook on the $8^{\text {th. }}$ The findings of the study show that almost the merits and demerits of the textbook are equal. Demerits include a lack of focus on language skills and sub-skills. Other aspects of language learning have also been ignored, for example: need analysis, learners' age, background, learning style, examination equivalence, self revision exercises, achievement test, self-checks, supplementary material, audiovisual recording. This study concludes that the school management should replace or revise the contents of the textbook.
\end{abstract}

Keywords: Checklist Method, Impressionistic Method, Evaluation, ELT Material, ELT Text Book Introduction

The word 'evaluation' is used to point out the rightness or wrongness of something or somebody. Evaluation is also a process in which, the fitness of something or somebody is assessed. Hutchinson and Waters (1987) further throws light on the term that it is a process in which judgment is passed to regarding the suitability of the material which is to be used to achieve a particular goal. Evaluation aims to assess curriculum, programs, and interventions, teaching methods, and organizational issues. An evaluation is a very complicated notion that incorporates several stages, for example, it contains the stages of the selection of the information, transference, and analysis. Evaluation is also employed to decide the fitness of the curriculum.

An evaluation is a highly imperative and central facet of an educational organization of the country. Based on the evaluation, curriculum policies can be developed, feedback can be taken on the ongoing curriculum, and the curriculum can be adjusted and implemented. Cronbach (1963) holds the view that the process of the evaluation must pay attention to collecting and providing such information as could effectively aid in deciding an educational program and syllabus design. Hence, textbook evaluation is also thought to be playing the role of educational judgment.

According to (Tomlinson, 1998) an attempt is made to assess the worth of published material. There is a technical difference between the two-word terms 'analyses concerning their goals. Analysis and evaluation are described differently by the syllabus designer and course designer. In line with (Littlejohn, 1998), evaluation is the simplest process in which the evaluator makes an effort to find out what is there, on the contrary, according to (McGrath, 2002) the main aim of the evaluation is to see if the required material/substance which $t$ the evaluator is looking for is there, if he finds them, value must be put on the material.

English language textbooks are viewed as an indispensable constituent of the EFL course. It is also stated by Richards and Rodgers (2001) that textbooks are inevitable components of the given

\footnotetext{
* Govt. College University, Faisalabad. Email: abdulalipcc@ gmail.com

** Department of English GC Women University, Faisalabad. Email: amarajaved@ gcwuf.edu.pk

*** Department of English, GCU, Faisalabad. Email: drgmaatir@gcuf.edu.pk
} 
curriculum. They cannot be ignored. The course books also spell out the content of the syllabus and define the coverage of its items. Grant (1987) further throws light on the importance of the course books by mentioning that they offer opportunities to the language learners to work out the problems by applying a second language in the ELT classroom, which is taken practice field before using them in the authentic world. Some of the applied linguists take textbooks as a magical wand which gives them an idea of structure, unity, and growth. Besides, the coursebook also assists language learners to realize stability and persistence (Littlejohn, 1998). Nonetheless, many experts argue that coursebooks are certainly shallow. The coursebook tends to reduce the range of language items and they put on homogeneity course contents, moreover, the teacher cannot make any urgent and necessary change that is effective and productive for the learners. (Basturkman, 1999; Byrd, 2001; Hutchinson \& Torres, 1994; Tomlinson, 1998). Therefore, if a most befitting book has to be selected for a particular class or program, it must be carefully put through the process of evaluation. Sheldon (1987) defines that textbooks are published materials that are tailored to facilitate learners to enhance their linguistic and communication skills. The EFL printed material is much more in use in the present times than it was in the past, because published textbooks offer techniques to the teachers about their syllabus, offer methods of teaching and new ways to teach the material. The contents of the textbook must provide all the required skills to the student by learning those skills, they could communicate comfortably and confidently. Besides, after reading those contents, they must be able to utilize linguistic elements in real-life situations or in a society in which they live.

The material of the textbook should neither be too difficult not it should be too easy, if it is so, ultimately, the teacher will come across many problems. It proved here that the contents of the text should be moderate and balanced.

When a textbook is selected, it is highly imperative to put it through evaluation, just to make sure, if the book is fit/suitable or not. Moreover, no doubt, fundamentally, the textbooks are used as learning tools at the same time; they are also used as supporting tools for teaching purposes, all published material is prepared so that could it afford cohesion to language learning and language teaching (Masuhara \& Tomlinson, 2008).

The present study also evaluates in using the English language text book "Oxford Progressive English for 8th class, written by Rachel Redford. The book is used in Allied School Faisalabad, A project of Punjab Group Colleges. The book is also taught in almost 40 Allied Schools in the Punjab province.

\section{Methods of Text Book Evaluation}

According to McGrath (2000) textbooks can be evaluated through three methods: (1) Impressionistic Method (2) Impressionistic Method (3) In-depth Method. Widodo (2015) Impressionistic method indicates a general way of reading and then summarizing the contents presented in English textbook. In other words, the contents are evaluated at the surface level. Another popular method is the checklist method in which the textbook is evaluated against some criteria (Çakit, 2006). A similar view is held by Widodo (2015) through checklists; the contents of the textbook can be compared, verified, or identified. A third well-known technique is the "In-depth Method" which offers a careful analysis of the specific linguistic and non-linguistic components (Montasser, 2013).

\section{Statement of the Problem}

English as a second language is taught in Pakistan. English is being taught in this part of the world for many years. For a long time, the structural approach to language learning remained in practice. Widdowson (1972, 15-19) argues that it is an enormous problem for learners who learn English through a formal/structural approach for many years, they remain inefficient and unable to use and understand language in the realistic context of the world life. However, in the wake of the "Communicative Approach" which argues that language is a tool to produce "Communicative" ability among the learners and use language in a real-life situation. As result, teaching and learning material whether it is curriculum, syllabus, textbook, and methodology must be based on communicative skills. Though curriculum and syllabus are designed at the local level, however, the textbook is exported. Most of the private and semi-government prefer to impose Oxford and Cambridge book texts. The suitability and worth of English textbook is a huge issue and problem. Where the textbook is suitable or fit to be taught is a serious issue. The present research is conducted to evaluate the suitability and fitness of the in-use textbook: Oxford Progressive for the $8^{\text {th }}$ class being taught in Allied Schools 
Faisalabad. The results of this investigation can be a valuable asset for the Allied school administration.

\section{Significance of the Study}

Textbook and curriculum evaluation is in progress in Pakistan. The textbook evaluation is a weak link in the language education program; it is not fully mature and developed in Pakistan. Textbook evaluation is a highly organized and careful process because it has practical significance. The main purpose of this research is to evaluate Oxford Progressive for the $8^{\text {th }}$ class, whether it can fulfill the required needs of the learners. Besides, it will also be assessed if contents, tasks, and language skills synchronize with a communicative approach. The findings of this study have significance for the curriculum and, syllabus experts, textbook writers and evaluators, teachers, and learners.

\section{Research Questions}

1. What are the merits and demerits of Oxford Progressive for the $8^{\text {th }}$ class?

2. Should the textbook be revised?

\section{Literature Review}

A good many researchers have conducted researches on the textbook evaluation, those researches are given below.

Fredriksson and Olsson (2006) also conducted a similar examination to probe the criteria for the selection of the textbooks. They explored in what way the ELT teachers handle the challenge when they have to select ELT coursebooks for upper secondary. The findings of the results of this evaluative study show that the best standard the teachers adopted was to select entertaining and relevant books. Texts should make them able to use language in a real-life situation. Teachers argue that diversity and motivation in the English language textbooks are highly important to teachers a well as learners. Based on it can be surmised that ELT textbooks ought to be entertaining and interesting, but it does not tell in what manners textbooks can be made interesting and entertaining.

Cakit (2006) also conducted a study to seek opinions of teachers and students on English language textbook for 9th class for high school. The participants of this assessment expressed a negative attitude about most of the components of the English textbook. The researcher has suggested that reading passages in the textbook needs to be simplified regarding vocabulary and grammatical patterns .it is suggested learning material should be brought to the level of the age of the learners. Finally, the textbook writers /authors must take into consideration the learners preferred style. This study is weak concerning the research paradigm, data collection, and data analysis procedures.

A similar examination was conducted by Al-Yousef (2007) in Saudi Arabia to evaluate the New Third Grade Intermediate English textbook. The nature of the research was qualitative as well as quantitative. The teachers, supervisors including 184 learners took part in this evaluative process. The findings of both methodologies (qualitative and quantitative) research revealed that participants expressed a highly positive attitude towards their recommended textbook since the average mean was 2.0 out of 4.0. The highest mean was displayed by the contents and visuals on the other hand; additional materials, grading, and recycling obtained the lowest mean. In addition to this, in the Iranian context, the domain textbook evaluation has been of great interest. The second reason could be that now a day, the Iranian educational stakeholders and educational policymakers are making some of the changes in their curriculum. It can be said that students like ELT textbooks are based on contents and visuals. It meant that textbook designers must incorporate visual contents to make the textbook interesting

One more study was conducted in a similar context by Jahangir (2007) who selected English coursebooks which were taught from the first level to the last level of year before university level ELT material. It is revealed through findings that ELT material of 'Pre-University' shows optimal strength which can enhance the students' knowledge, learning techniques. Whereas, first grade, second grade, and third grade English textbook need to be revised and reconsidered. One of the weaknesses of this research is that it does not explicitly mentions the weaknesses and strengths of the study. This study also does not describes why it should be revised.

Almari (2008) conducted a study in the Saudi Arabian background to check the ELT coursebook. The researcher selected the 6th class English textbook for boys' was selected to be evaluated. The Ministry of education launched this textbook for the schools at the elementary level. As a research tool, a questionnaire was employed for the evaluation of the textbook. The data has been analyzed through the "SPSS" software used for numerical figures. It was found that both the 
teachers and supervisors were generally satisfied in terms of layout, illustrations, supplementary material, prescribed objectives, topic appropriateness, and linguistic elements. At the same time, the results also demonstrate some demerits: (1) the textbook lacks diversity and eye-catching illustration which will encourage creativity (2) the textbook lack topics that ignite critical thinking among the students.

Mahmood et al. (2009) evaluated English language text in Pakistan as well as outside Pakistan The researchers argued that there was no suitable standard available to evaluate textbooks. As a result, they conducted the research to set the standard for review, evaluate, and approve the quality of the given textbooks. They used and developed Garvin's (1988) evaluating criterion to check the value and the worth of the textbook. It can be concluded that they developed a new model for the evaluation of the ELT textbook.

Safarnavadeh et al. (2009) examined to evaluation of the textbook. The findings of this evaluative work exhibited that the main purpose of the textbook was obtained through linguistic elements. The basis of these linguistic components was the structural approach. Writing skills that laid heavy stress on the grammatical preciseness as a result it got much more prominent than other linguistic skills. The writing skill was set in the textbook in a traditional style, with some balance of difficulty and mechanistic applications and models were also observed. They also found that the nature of the contents and activities were of too conventional and routine methods were followed. The findings of this evaluation study show clearly that the textbook needs some revisions in it. The study aimed to analyze linguistic features in the textbook. One of the weaknesses of the study was that it ignored the cultural and pragmatic aspects of language. Based on the findings it may be inferred that the textbook designers should avoid the inclusion of traditional and customary methods.

Tok (2010) also attempted an evaluative study on an English coursebook titled "Spot on". The textbook is taught at the primary level in Turkey. English textbook was put through the due process of evaluation. The findings of the research revealed that there were some merits and demerits in the textbook. The best quality of the textbook was that it did focus on a single culture. Besides, the textbook also guides the teachers about how to make use of it. On the contrary, it has some demerits, for example, first, it lacks interesting activities. Secondly, helping material was not supplied along with the activities to achieve the objectives. Finally, it lacks activities which develop communicative skills. Based on the findings of the study, it can be concluded that the textbook should include both local and target culture; it should include interesting tasks and activities. One of the weaknesses of the research is that it was not a local one, it also neither mentions its research neither methodology nor research paradigm.

Like other studies on evaluation of the textbooks Kiyani et al. (2011) also conducted the study to evaluate the textbook. In their examination, the researchers talk about their state curriculum for teaching English as a second language. The curriculum is discussed with three important aspects. The researchers bring to light a good number of positive points in the curriculum, for example, it centralizes the role of learners and it increases the time duration for teaching English ESL from a minimum of 485 to 596 maximum hours in both grades of the school. Yet, the same state curriculum also reflects some negative points. The harmony and accordance among prescribed and set goals for the pedagogy of English as a foreign language. The curriculum is short of expert / skilled individuals who permit these textbooks. The urgency for needs analysis has been ignored altogether. Based on the findings of the study the conclusion can be drawn that disharmony between the goals will not generate positive results. It also meant that the curriculum developers are not skilled in their relevant fields.

Perveen (2011) also researched the evaluation of the curriculum of the primary school level. The purpose of the investigation was to check whether the objectives of the curriculum are in line with Pakistani education policy and planning. The study also analyzes how the objectives of the national curriculum have been achieved through the language policy and planning. The findings of the examination indicate that the curriculum objectives were not obtained maximally. It meant that the stakeholders followed weak procedures to implement education policies and planning concerning the primary curriculum. It can be argued that disharmony among the objectives of the curriculum can lead to negative output

Like other studies on evaluation of the textbooks Kiyani et al. (2011) also conducted the study to evaluate the textbook. In their examination, the researchers talk about their state curriculum for teaching English as a second language. The curriculum is discussed with three important aspects. The 
researchers bring to light a good number of positive points in the curriculum, for example, it centralizes the role of learners and it increases the time duration for teaching English ESL from a minimum of 485 to 596 maximum hours in both grades of the school. Yet, the same state curriculum also reflects some negative points. The harmony and accordance among prescribed and set goals for the pedagogy of English as a foreign language. The curriculum is short of expert / skilled individuals who permit these textbooks. The urgency for needs analysis has been ignored altogether. Based on the findings of the study the conclusion can be drawn that disharmony between the goals will not generate positive results. It also meant that the curriculum developers are not skilled in their relevant fields.

Kohlrabi (2012) also assessed the weakness along with strengthens the ELT course book for High School Freshmen in the Iranian academic context. The study attempted to seek how teachers and students express their perspectives on the ELT material. They focused on seven sections of layout, vocabulary, topics and content, exercises, skills, pronunciation, function, and social and cultural activities. The results of the investigation showed that ELT textbooks were grammar oriented, it mainly focused on the reading skill whereas other language skills were overlooked. Moreover, it lacked adequate drills pronunciation. It also lacked cultural activities, social activities concerning second language culture. At the same time, the layout of the book lacked beauty.

A similar research was conducted by Aftab et al (2014) who analyzed ELT material "Prose and Heroes" which is taught at the Intermediate level in the Pakistani context. The basic aim of the investigation was to contribute to boosting ESL programs, being held in Pakistani colleges. The investigation was based on the exploration and description of the data. The study used questionnaires along with semi-structured interviews. The results of the evaluation exhibit that the selected English textbook lacks optimum quality to serve the demands of the learners. The findings of the study fail to mention recommendations concerning enhancing the maximum quality of the proposed textbooks.

After reviewing the above literature, the researcher has concluded all the ELT studies were conducted in the global context, there were only two studies that were conducted in the local context. As result, the present research will fill the gap in the evaluation of ELT textbooks in the local context. The present study aims to evaluate the Oxford Progressive Book for the $8^{\text {th }}$ class by using the Sheldon checklist. This research is qualitative.

\section{Research Design}

The nature of the present research on the evaluation is of descriptive qualitative. It is qualitative because the purpose of the study is to find out the merits and demerits of the textbook. It is also descriptive because it uses the content analysis technique to evaluate the data. Content analysis aims to analyze data qualitatively (Anderson, 2007).

\section{Data Collection}

For the present research, the data has been collected from the Oxford Progressive for $8^{\text {th }}$ class which is taught in all Allied School Campuses in Faisalabad. The data has also been collected from the lessons/topics, exercises, and activities and sections as well.

\section{Data Analysis Techniques}

Concerning the data analysis of the present examination, the researcher has singled out the technique of content analysis.

\section{Sample for this Research}

Oxford Progressive Press has written ELT textbooks from class 1 to class $10^{\text {th }}$, it was impossible to evaluate 10 books with short space and time. As a result, the researcher has selected only Oxford Progressive for the $8^{\text {th }}$ class which is taught in all Allied School Campuses in Faisalabad.

\section{Research Instruments}

Checklist Method and Impressionistic Method" as an instrument will be used to evaluate the Oxford Progressive textbook for $8^{\text {th }}$ class. Though there is an array of checklist, yet the researcher has prepared his checklist by reviewing the literature on checklists. After reading checklist literature, the researcher took some points from Sheldon (1988), some points from Celce-Murcia (1979), and some from Asma (2011) while some from points Mukundan, Haji Mohammad, Ninehchisalem (2011), so the new checklist prepared by the researcher is given below:

(1) Rationale (2) Availably (3) User Definition (4) Layout and Graphics (4) Accessibility (5) Physical Characteristics (6) Appropriacy (7) Authentic Material (8) Sufficiency (9) Cultural Bias (10) Stimulus Sheldon (1988 (11) Cognition Asma (2011) (12) Language skills: Listening, speaking. 
Reading and writing Mukundan, Haji Mohammad, Ninehchisalem (2011 (13) Vocabulary (14) Grammar Celce-Murcia (1979)

Moreover, the checklist also covers the principles of the communicative approach. Almost all checklists that have been prepared are based on the communicative language approach.

Findings and Discussion

Sheldon's ELT Textbook Evaluation Checklist

Textbook Evaluation

Title: Oxford Progressive English

Author(s): Rachel Redford

Publisher: Oxford University Press

No. of Pages: 276

Level: 8 th class

Physical size: length 11 inch and width 9.5 inch

Length: ........ Units 10 Lessons/sections 50 Hours: Not mentioned

Target skills: Listening, Speaking, Reading, and Writing

Target learners: Pakistani Urdu speaking children

Target teachers: Pakistani Urdu speaking teachers

A: Rationale

1. What was the foremost purpose of writing this book and what gaps it is intended to fill?

Firstly, the Oxford Progressive book was authored in line with the U.K and Pakistani curriculum goals. The book aimed to build up linguistic skills for the learners. The four national languages have been focused to produce communicative competence among the learners by way of practicing speaking tasks, listen to tasks, reading tasks, and writing tasks. The book is well-organized and structured, progresses gradually. The book intends to cover all four language skills.

Secondly, According to (Crookes \& Chaudron, 1991) textbooks are also printed because there is pressure and competition in the market to bring out such products. (Sheldon, 1987) deems that ELT textbooks are printed to gain commercial profit. Morris (1995) considers English textbooks as market leader (p. 117). It is further argued by (Morris, 1995) that textbooks are a huge business to earn income and make a profit. The publishing company is more conscious about the selling of textbooks; they have nothing to do with the curriculum. Hong Kong earned an enormous profit from textbooks at the higher secondary level. The country earned 6 billion US dollars in the year of 1999.

2. Has the writer conducted a need analysis before recommending the textbook?

Nothing has been providing about Need Analysis and no was classroom piloting undertaken. Nunan and Lamb (1996) consider that" Needs Analysis" supplies the foundation to textbook writers so that they could set goals and objectives. Johns (1991) also thinks that needs analysis is an inevitable component of the language course. Need analysis to guarantee that all tasks in each unit are relevant and valid?

3. Are the objectives spelled out?

Yes. In the content section, the learning objectives have been provided clearly at the end of lessons. For example, after the conclusion, of the first unit, learning objectives are as follow:

(a) To introduce different kinds of writing.

(b) To decipher the text and interpretation of ELT textbooks.

(c) To identify and understand the meanings of words and expressions.

Similarly, learning objectives have also been given skill-wise, for example. In the unit: 6 , the learning objectives of the Grammar are:

(a) Personification

(b) Direct speech, description, facts and opinions

In the same fashion, in the unit: 6, the learning objectives of Writing are:

(a) to write imaginatively

(b) to select details for a newspaper report

(c) to write clearly and simply

(d) To understand abbreviations used for figures. 
To sum up, the learning objectives have been given "Unit" wise and "Skill" wise in this English textbook for $8^{\text {th }}$ class.

\section{Availability}

4. Can sample textbooks and supplementary material can easily if needed for reading /studying?

Another factor in the evaluation of the textbook is its availability. The book on hand is available very easily and comfortably from the market. The book can be had from all local book shops. Besides, it can also be taken from Oxford's book centers which are present in every big city. A textbook should be in print and be ever available.

5. If further detail is required concerning the subject matter, approach, and teaching of this book, can you contact the publisher's representative?

Oxford Press is worldwide famous and it has branches in the UK and certain countries. The products of Oxford Press are also published in Pakistan.

User Definition

Yes, we can make a contact with the representatives.

6. Does it meet cultural, age, and educational expectations?

No. Another important fact factor is the user definition. In the present book of the $8^{\text {th }}$ class, no explicit details have been furnished for age, culture, context, preferred learning styles, and education expectations from the learners. Not a single lesson based on the local culture has been found in the textbook. If social and economic circumstances are not good, the learners will come across some problems in second language acquiring and (Khattak et al., 2011) is claimed by McKay $(2000,2002)$ emphasized that language materials must incorporate a diversity of cultural factors. Material must include local culture, target cultural and international culture to language learning interesting, motivating for the learners. Similarly, learning styles also play a key role in language learning; according to Gordon (1998), learning styles put their influence on the learning procedure. If the teachers and students are well aware of the learning style, students can show the best performance they have also been set aside by the author of the book.

7. Does it meet International standards of examinations?

Grant (1987) states that ELT material ought to answer the needs of every executive public exam. The author of the textbook has not provided any entry-level or exit level of language. It is not mentioned anywhere that the current book is minimally or maximally equivalent to IELTS, ACTFL, CEFR (A1, A2, B1, B3, C1, C2 levels of language). In the same way, the writer of the textbook also does not mention how this English text book can fulfill the requirement of the local examination. To sum up, details about the level of language, about international and local exams have been left out altogether.

Layout and Graphics

8. How is the textual and organization layout of the text.

The textbook has a host of pictures that are true to life. Colour photographs and drawings have been added book. Vetter, Ward, and Shapiro (1995) claim that if color is added during the classroom instruction, it can boost students' performance. It has a clear layout and wellorganized. Angeli \& Valanides (2004) claim that visuals in the textual explanation can enhance comprehension and operation of visuals stands on mental differences. The title of each chapter is well written. The font size of all the reading texts is befitting. The structure of the text is uncluttered. The visuals and text is stuffed into each other. Students can see find their path with ease and comfort. The images and pictures are from the real world and purposeful.

9. Does the font size and print typefaces make it attractive?

Font size, book size, and printed text, no doubt, make reading easy and comfortable for the students. For all letters, black color has been applied. Appropriate space is given from words to paragraphs. A good quality issued in the text. An excellent artwork and typefaces have been displayed in the book. The artwork leaves a positive effect on the student and motivates them for reading. All the artwork is very colorful and appealing as well.

Some researchers (Ambrose \& Harris, 2005; Brady, 1993; Clinton, 2003; Ferrari \& Short, 2002; Gates, n.d.; Monotype, 1997) conducted researches to find out the best font, whether 
Font: Times New Romans or Verdana should be used for the readability and comprehension of the text. The results of their investigation showed that Times New Roman, that is, serif fonts are suitable for printed media. Times New Roman, 12 fonts have been used which standard for the textbook. To wrap up, artwork, typefaces are attractive and functional. In other words, they have been used logically, not randomly.

Accessibility should be the topics/text familiar to the learners.

10. Is there a clear organization of textual materials?

The material of the textbook has been evenly organized and sequenced. However, the topics are not related to each other. The book is divided into 10 Units and the Units are further divided into 5 lessons each and then each lesson is divided into a minimum of 4 and a maximum of 8 paragraphs. All paragraphs have been assigned numbers. In addition to this, all paragraphs are left-aligned. The topics and heading are boldfaced and can be seen. There is a diversity of topics that halts monotony and increase the interest level of the readers. Almost all literary and non-literary genres have been provided and introduced into the book, for example, poetry, biography, fiction, advertisement, and newspaper. The nature of the topics is general and familiar.

11. Does this book guide us about learning progress, what has been learned and what remains yet to be learned?

No such thing has been mentioned in the textbook. No criterion has been suggested to the readers. There is no such point/place in the textbook which could the readers about their level of language learning. Learners cannot judge their progress at any stage in the book. Students cannot judge how much he achieved and what more left behind to achieve in other words, there are no assessment tests/exercises for the students by following they could measure their progress in language learning. CEFR has also introduced different levels of learning. For example, level 1, A2, B1, B2, C1, C2; all these show different levels of learning. At level A1, the student has to learn simple content of language, and then he will move onto the A2 level. After learning A2 level language content he will move onto B1 and so on and on.

12. Does this book guide the students about self-study, revision, vocabulary, and other contents?

The answer to the above question is partially yes. Indexes, vocabulary lists, and section heading have been supplied explicitly. For example, on the page \# 56 the following section heading are given:

(1) Reading for detail

(2) Reading for Understanding

(3) Vocabulary lists

(4) Three quick questions on meaning

As regards, revision, and self -study for the students, the textbook writer has not provided any material whatsoever. The absence of the revision and self-study material is a glaring deficiency in the book.

13. Does this book suggest how can a learner use ELT material appropriately?

At this level, the students are not able to pass their judgment regarding the use of the content of the book. However, when advice sought from the teacher, he opined that vocabulary has not been recycled; rather, its nature is linear. Adequate vocabulary exercises would do a good deal. As all units are based on non-native culture which involves an issue of intelligibility. Lesson based on native culture increases the comprehensibility of the lesson.

Physical characteristics

14. Has margins been provided in the books?

Yes, the present textbook has provided space on the left side of the book. Almost 3 to 4 inches of space has been provided to write short notes there.

15. Is the book strong, light, or weighty?

Yes, the current English textbook is very robust and it can withstand wear and tear easily. The length of the book is normal and its weight is also normal. The students of the $8^{\text {th }}$ class can take the textbook anywhere. In case, textbooks are overweight, and create problems for the student. The State must go for the lighter weight textbooks. The maximum of the textbooks should be from 5 pounds to a minimum of 3 pounds. 
16. Is the spine labeled?

Yes, the spine of the book has been labeled as Redford Oxford Progressive English

17. How many times these books can be used after it has been used one time?

No, this book can be used only one time. If past students have put marks on it or has written some notes on it. The durability aspect of the book is a little weak.

Appropriateness

18. Is the material significant enough or appealing for the students?

Another feature of the textbook is that it must be appropriate in the sense that it should be boredom free, students must be taking interest. Some units capture the attention of the students, for example, Great Invention (P.2) Horses, (P.29) Food (P.138) Railways (P112) and Money (P.192).

19. Is it topical?

No, the English textbook is not topical, in other words, it does not throw light on contemporary issues. There is hardly any topic which is related to the recent times. Most of the units and topics under them are so very simple and ordinary. We can judge by the name of units of the book, for example, Horses, Food, Conflict, Belonging, and Money are routine topics. No modern topics like computer, mobile, terrorism, unemployment, and freedom and sports are not found in the English textbook. We can also argue that religious, social, and media related are left.

20. Does its material matches with the conceptual levels and language level of the students. Yes, the textbook matches with conceptual and language level of the student.

Authenticity [Authentic material]

21. Are the course contents from real-life situations or it is otherwise?

The material is not authentic. Most of the topics are non-authentic: Unit 10, Unit 8, Unit 7, Unit 3, and Unit 5. The material is not taken from L1. The positive features of the authentic materials are that they offer an opportunity to come face to face real English language. The authentic materials also motivate the learners to provide cultural information and hence increase their success in the long run (Richards, 2001).

22. Do the tasks of the books CLT?

Regarding the criteria of communicative language and realistic language content, Richards and Rogers (1986), cited in White (2009), stated that the primary function of language is for interaction and communication.

23. Is the text abridged or non-abridged?

The text of the non-authentic text is simplified, on the other hand, the text taken from authentic sources are not artificial or simplified, for example, Unit 1 Newspaper reports, Unit5, Newspaper article and magazine advertisement. Yet, the simplified texts are acceptable.

\section{Sufficiency}

Widdowson (cited in Baghban, 2011)

24. Is the book complete enough to stand alone and independently?

No, the book is not competing. It is not self-reliance. Supplementary textbooks deal with things that are interesting and include little if any uninteresting things (Maley, 1989). It demands additional staff to work it work appropriately. It needs CDs, cassettes and movies

Cultural Bias and cartoons like additional material.

25. How have social and religious topics been dealt or they have been missed out?

No religious topics have been presented in the ELT textbook of any kind. Nonetheless, Unit 4, Unit 6, Unit 7, and Unit 8 depict the social environment in the book. These topics and situations do not make good to those who have been left out.

26. Has methodology regarding contents been set in the according to anticipations of the students?

The ELT materials showcase conventional and automatic contents and activities which can be classified as excellent methodology. It is stated that ELT "Writing Material" and "Reading Material" always feature flexibility, for example, listening material consists of integrated elements, and that is, speaking, pronunciation, and grammar, it proved that ELT material has 
to be flexible. On the contrary, mostly, the ELT material is seen as over-burdened. As a result, it causes difficulties for weak learners and beguines.

27. Does the coursebook show stereotypes and negative ideologies of gender, race, social class, or nationality?

According to Spicuzza (2009) cited in Yulianti (2011), the materials in the textbook should not be culturally biased. His findings reveal, that the textbooks he explored have not stereotypes elements and it does not show unpleasant images. The social ideologies are not biased. The material of the book is impartial and poised.

28. Is the author's sense of humor or philosophy obvious or appropriate?

Yes, Research shows that the positive impact of humor on language learning is obvious (Deneire, 1995).it enhances critical thinking in learners. It also bring down anxiety and stress (Berk, 2000). The humor is set appropriately English textbook. One can see humor in pardoner's tale Unit 1 and Unit 9. The humor is very light and controlled.

29. Have the picture of America and Brittan been depicted positively? How social bitter realities been presented in the text? Or they have been missed out?

Yes, painful social realities of Britain or America have not been incorporated in the present English textbook. Whereas Sheldon (1988) suggests that the social realities about The USA culture and Brian should be positively mentioned.

30. Does the course work offer suitable material based on interaction?

Yes. It offers activities based on interaction

31. Does the textbook offer revision, test activities, and self- checks?

A close inspection of the activities and tasks of the textbook shows that it follows the P-P-P approach for teaching grammar and does not focus on consciousness-raising and discovery learning tasks. It does not offer a diversity pair, group work. The book is short of discussion, activities, and tasks. No, the textbook fails to provide tailor-made testing. Test development is altogether handed over to the ELT teacher. Besides, No, the book lacks self-checks exercises.

\section{Cognition}

32. Are the activities cognitively appropriate for the content?

Yes, the activities in the given textbook are cognitively appropriate. The writer of the book has touched upon almost all levels of Blooms' taxonomy. The activities have been designed at the knowledge level, comprehension level, application level, synthesis level, and evaluation level. For example, in Unit $1 \mathrm{Q}$ match the following words from the text on the left with definitions in the right-hand column (page 21) knowledge level. Explain how Clive made his train? Comprehension level. The main focus has been on the lower order cognitive skill, that is, knowledge and comprehension level.

33. Does it cater to the needs of different learning styles?

Partially yes, there are well over 70 different learning styles schemes (Coffield, 2004). However, the book mainly focuses on the two types of learners: visual and global and sensor learners. Nonetheless, it has been ignored by kinaesthetic and tactile learners.

34. Do activities activate previous knowledge?

Yes, the activities of the book has been designed and organized in such a way that it activates previous knowledge. For example, the activity Reading for Understanding is followed by the activity Reading for detail, so to do the latter activity, the former activity will activate the knowledge.

35. Are activities challenging?

Yes, as for reading activities are concerned, they are indeed challenging, the reading activities which are based on inference, visualization, and interpretation, are taxing. If someone can make inference, he can be called a successful and good reader (Anderson \& Pearson 1984).

36. Do activities include projects?

Yes, in the present book the activities include projects, for example, on page 23, page 27, page 65 , page 95 projects are given to work on by the pair or the group.

Erdem (2012) who found that project-based learning could promote students' enthusiasm towards learning. She stated that Project-Based Learning was able to increase students' 
enthusiasm towards learning. When the children are excited and enthusiastic about what they are learning, they often get more involved in the subject; the level of anxiety is reduced and then expands their interest to other materials. Enthusiastic students tend to retain what they learn, not to forget it as soon as they have passed the test

37. Are activities motivating?

No, the present book mainly focuses on the static experienced tasks, static guided tasks, and static shared tasks (Finch, 1999). Static tasks create boredom; they pay attention to vocabulary, grammar, and comprehension, on the other hand, dynamic task are motivating and interesting .hence, the present book lack dynamic/two-way tasks.

Representation of Language Skills Listening

38. Has the book mentioned listening tasks with learning objective and learning outcomes?

Yes, the book mentions the learning objectives and learning outcomes for listening skills. Listening skill tasks are prevalent throughout the current textbook. Everson (2009) explains that listening is a vital skill of language in the sense that it enables one to be able to understand what other people are saying or communicating.

39. Are the tasks authentic and close to real-life situations?

No, most of the tasks are not based on authentic texts. They are based on the lesson.

Harmer (2001) argues that students can enhance their language production and language acquisition if the material is authentic. It also adds to their level of confidence, when they use language in real contexts.

40. Are instructions given clearly?

Yes, the instructions have been supplied clearly in the textbook, for, example, in the Writing task, page (66) the instruction is given in the following way.

Write the story of the Listeners and The Traveller

- Use any of your ideas which you worked out in your listening and speaking group.

- Use besides, if you wish, any ideas which you have heard in your group.

- Use any fresh ideas which you may have.

- Use vivid descriptions and creative words.

- $\quad$ Make it gripping and exciting

41. Are tasks efficiently graded according to complexity?

Yes, the task are sequenced and graded according to the, for example, Reading tasks are sequenced as (i) reading for understanding and then (ii) reading for inference (iii) followed by reading for imagination and (iv) reading for interpretation. As the books progress the complexity level increases.

\section{Speaking}

42. Are speaking activities developed to initiate meaningful communication?

No, speaking has been ignored completely. The degree of communicativeness is zero. There are not structured or authentic communicative activities, in the Littlewood (2004).

43. Are speaking activities motivating the students for communication?

No, speaking activities badly fail to ignite the student to speak English. No role play, no jigsaw no drills have been designed for the students.

44. Is pronunciation skill-focused?

No, pronunciation skill has been focused, despite the fact; pronunciation is an integral part of speaking. No guidance or information has been dished out in the current textbook about Reading segmental and suprasegmental features of language.

45. Are texts arranged?

Yes, the texts/genres are arranged in a spiral fashion, not in a linear fashion. The units have been divided into topics and topics into numbered paragraphs. The average word length of the paragraph is 250 , which is easy to understand for the students. All activities in the present textbook are based on PPP. P1 activity is the presenting stage, P2 is the practice stage and P3 is the production stage. However, form has been preferred over meaning. 
46. Do the texts appropriate lengthwise?

No, the length of the text varies from one lesson to another lesson. The length of the lesson varies, the reason for which could be different text types / different genre types. There is a diversity of text length in the text lessons.

47. Has any reading model applied/ followed $\backslash$ used in the reading activities?

No, whereas, in pre-reading activities, the students are introduced with background knowledge, this introduction activates essential schema (Carter \& Long, 1991). In whilereading, on the other hand, exercises help students develop reading strategies. And finally in the post-reading students check their level of comprehension which leads them to an in-depth analysis of the text (Ibid: 16).

\section{Writing}

48. Do the writing tasks have achieved goals and take into account learners' abilities?

No, most of the writing tasks failed to realize the learning goal on account of task complexity. Also, there are inadequate samples/opportunities for the learners to practice writing. The textbook is weighted with guided writing and lacks other writing types, for example, controlled writing, translation, and free writing.

49. Have models been provided for different genres?

No, model for different genres have not been provided, for example, on page 106, the students are asked to write a letter to the editor like this:

\section{Writing Task}

Q1 Write a letter to the editor in which you describe your perfect world. Page 106

Here no model available, no guidance regarding the genre structure of the Letter to the Editor.

Write a story, using the poem, The Human Heart, or one of the proverbs, as your inspiration. P.237. Again no story writing model has been supplied. No guidance regarding parts of the story and language of the story.

\section{Are tasks creative?}

Yes, tasks are creative. However, these tasks are not in line with David Nunan (1999) classification tasks: (1) cognitive tasks (2) Interpersonal tasks (3) Linguistic tasks (4) Vocabulary Affective tasks (5) Creative tasks. The English textbook bare covers these task types.

51. Is the load (number of new words in each lesson) appropriate to the level of learners? Yes, new words are set in the lessons, but they are only specific to that lesson.

52. Are the vocabulary items controlled to ensure systematic gradation from simple to complex items?

No, on page 7, Unit1, at the very start, complex vocabulary is introduced.

$\mathrm{Q}$ at page 7: The following are the anagrams of words from the text connected with the lesson Circus

Can you solve them?

(1) JOCUREN

(2) STAROBAC

(3) SHEEPLANT

(4) KIRRISDRECT

(5) SCINISAMU

Is this simple vocabulary?

In the same fashion, Unit 2 also starts with a special vocabulary. The textbooks take inverse start, namely, instead of starting from simple vocabulary, it is staring from complex and technical words.

53. Is there a repetition of the fresh vocabulary items in the following lessons so that students can memorize it properly?

There is no repetition in the following lessons for the students to make them stronger. The vocabulary move s in linear order instead of cyclic order. Whereas Nation argues that (2001: 77) the repetition is a medium through which students can enhance their vocabulary acquisition both qualitatively and quantitatively. 


\section{Are words contextualized?}

Yes, the words are contextualized. Finocchiaro and Brumfit (1983) studied the role of context in the communicative approach. They claimed that language formal features should not be dealt with without its usage. That is to say, language teachers make sure they teach vocabulary in the communicative context (Beale, 2002).

55. Is the length of the sentence appropriate?

No, the situation is just the opposite, the length of the sentence is not reasonable. The majority of the sentences are too long to comprehend. The length of the sentences is not reasonable.

\section{Example page \# 17 Units 1}

Sentence length: "Other children, most of the admittedly older than I, but some of them infuriatingly not, constructed billy carts of advanced designed, with wooden frames and steel jacket ball race wheels that that screamed on the concrete footpaths like a diving Stuka.

Calculation through Text Analyzer

\begin{tabular}{ll}
\hline Number of characters (including spaces & 252 \\
\hline Number of characters (without spaces) & 208 \\
Number of words & 40 \\
Lexical Density & 90.0000 \\
Number of sentences : & 1 \\
Number of syllables & 66 \\
\hline
\end{tabular}

\section{Example Sentence length Unit 3}

"All nature was newly washed and it was impossible to work

Upon so delightful a day and I strolled out before breakfast to enjoy the exquisite air".

\section{Calculation Through Text Analyzer}

\begin{tabular}{ll}
\hline Number of characters (including spaces & 156 \\
\hline Number of characters (without spaces) & 119 \\
Number of words & 27 \\
Lexical Density & 88.8888 \\
Number of sentences : & 1 \\
Number of syllables & 43 \\
\hline
\end{tabular}

\section{Is the spread of grammar achievable?}

Yes, the spread of grammar is achievable. However, the grammar lacks systemic organization.

57. Does grammar moves from easy to complex?

Yes, the grammatical task moves from easy to complex.

58. Are examples easy in the textbook?

Yes, all examples are very easy. The student can develop his grammatical idea from the given examples easily.

59. Is grammar introduced explicitly?

Yes, grammar is introduced explicitly in the textbook. See example Book page: 102

Q Rewrite the following sentences using a word with one of the following prefixes:

$\begin{array}{ll}\text { (a) } & \text { Post- } \\ \text { (c) } & \text { Pre- } \\ \text { (d) } & \text { Ms- } \\ \text { (e) } & \text { Anti } \\ \text { (f) } & \text { semi- } \\ \text { (g) } & \text { half- }\end{array}$

The first one has been done for you as an example:

Bina is a very poor speller; she even spells her address wrong!

Change the italicized words into a verb with a prefix.

Answer: Bina is such a poor speller, she even misspells her address.

From the above example given on page 102, we can understand the grammar is introduced explicitly in the textbook. 


\section{Answer to the Question 1 \\ Merits of the textbook}

1. The textbook has been written to teaching four basic language skills.

2. Learning objectives have also been explained for each language skill and each unit.

3. Sample textbooks and supporting material for examination can be easily be obtained from anywhere.

4. Yes, we can make contact with publishers to get information regarding the content, approach, and teaching.

5. The page and paper quality, font, visuals, color, illustrations, the design is uncluttered, and means the student can understand clearly see their direction ahead.

6. Typefaces are attractive and functional. In other words, they have been used logically, not randomly.

7. The contents of the books are well-organized. The book is divided into 10 Units and the Units are further divided into 5 lessons each and then each lesson is divided into a minimum of 4 and a maximum of 8 paragraphs. The pattern is set concerning the organization of units.

8. Vocabulary lists, section headings, and other methods of signposting for the students.

9. Weight, length and width, left space, the spine of the book, and can be used more than once.

10. Material is motivating and interesting to draw the attention of the students.

11. The material / content level is beyond the level of conceptualization of the students.

12. Less authentic material has been used.

13. The text is simplified.

14. No culturally biased found.

15. No "Purified" views regarding England or America.

16. Questions /activities based on Bloom Taxonomy.

17. Vocabulary is the student level and contextualized.

\section{Answer to Question 1}

\section{Demerits}

1. No need for analysis has been conducted before recommending the book. Johns (1991) also considered needs analysis as the first part of the course design which provides relevancy and validity for the following activities which should be done in each course.

2. No information regarding age, culture, preferred learning style, and background educational expectations. According to Gordon (1998), learning styles have effects on the educational process, and how students perform. They have also been set aside by the author of the book.

3. Details about the level of language, about the international exam, and local exams have been left out altogether. According to Grant (1987), the textbook must meet the need for official public teaching syllabuses or examinations.

4. Learners cannot have a clear idea of what content/ skills they have achieved or what left to be achieved?

5. No tasks/topics for revision or self-study.

6. Neither teachers nor learners understand the utility of the textbook.

7. No modern topics like computer, mobile, economy, terrorism, politics, unemployment, and freedom, and sports are not found in the English textbook. Cunnings worth (1995) views that good textbooks incorporate topics and subject-matter from real-life situations and they are interesting as well.

8. The textbook does not match with the students' mental level.

9. Less authentic texts have been presented in the textbook. Authentic materials, on the other hand, provide students an opportunity to expose to real English, boost their motivation, provide cultural information and hence increase their success eventually argued by (Richards, 2001).

10. Tasks are not based on real-life situations.

11. The book is not self- sufficient. It needs supplementary material. (Brown, 1994) also argues that the language teacher should add supplement materials to promote motivation that is one of the key factors in language learning.

12. Revision testing, and on-going evaluation/marking of exercises and activities. No ready-made achievement tests provided for the coursebook, no 'self-checks' provided. Ur (1999) also 
states his view in favor of revision/ self-checks that "the learner can use self-checks to learn new material, review and monitor progress with some degree of autonomy" (p. 80).

13. The activities in the book lack projects. Moreover, the activities are not motivating. On the other hand, (Brewer \& Burgess, 2005) find motivation to be a basic and crucial part of the language of learning.

14. No audio - video cassette provided to better listening skills. No role play, dialogues interviews to practice listening. Oral activities and oral communication skills have not been focused on. No use of pre-listening activities, while listening activities and post-listening activities to develop listening skills. No authentic recoded material provided for listening to develop pronunciation, stress, intonation, pitch and accent, and accent variation. (Griffiths, 2011, Gilbert, 2010)also think pronunciation is highly important in a language teaching course, its importance is indisputable however satisfactory attention has not been afforded to it in textbooks.

As for speaking is concerned, Grant (1987) argues that a good textbook must carry three types of speech work (1) drills, (2) communication practice exercises to develop fluency, and (3) natural and spontaneous language. All three activities have been ignored in the textbook.

15. Reading tasks are set for individuals, not for pairs and groups. No pre-reading, while reading and post-reading activities cited in Karppinen (2013). The book loaded with open-ended questions, while other tasks, for example, information gap, multiple-choice, matching tasks, ordering tasks, summary, quizzes, role play and dichotomous items, translating word /phrases /sentences accorded less attention cited in Karppinen (2013). Mainly one goal of reading activities focused that is, understanding main ideas and details. Other goals, for example, author point of view, to get a personal response, reading text for writing cited in Karppinen (2013).

(18) No models were proved for writing genres. The textbook is weighted with guided writing and lacks other writing types, for example, controlled writing, translation, and free writing. Inadequate tasks for practicing writing.

(19) The vocabulary lacks easy to complex movement. New vocabulary is not repeated in the subsequent lessons to strengthen them. The length of the sentence varies from lesson to lesson and paragraph to paragraph.

(20) Inadequate tasks for grammar practice. The grammar tasks lack authentic language, contextualization, and collaboration (pair and group work), focus on form, Espeland T. (2017).

\section{Answer to Question 2}

\section{Should the textbook be revised?}

The results of the present study show that the Oxford Progressive for the $8^{\text {th }}$ class should be revised. There is a need dire need to focus on the tasks/ activities of the four fundamental language skills. Language tasks/activities have not been focused on. Apart from language skills, other aspects need to be focused on, for example: need analysis, learners' age, background, learning style, examination equivalence, self -revision exercises, achievement test, self-checks, supplementary material, audiovisual recording have also been ignored in the Oxford. If the aforementioned gaps are removed from the book, it can work very well for the learners. The course developers and language teachers must take care at the time of selecting and commending textbooks. We should also remember the quotation: Do not judge the book by its cover, in other words, other practical aspects must also be taken into consideration.

\section{Conclusion \& Recommendations}

This study has been conducted to evaluate the suitability and fitness of the Oxford Progress book for the $8^{\text {th }}$ level in Allied School in Faisalabad. The results of the study show that almost the merits and demerits of the textbook are equal. Demerits include a lack of focus on language skills and sub-skills. Other aspects of language learning have also been ignored, for example, need analysis, learners' age, background, learning style, examination equivalence, self -revision exercises, achievement test, selfchecks, supplementary material, audiovisual recording etc. The findings of this study have significance for ELT syllabus designers, ELT curriculum developers, and textbooks designers and to everyone who involves in the learning and teaching process especially in the field of teaching of 
English as a foreign language (TEFL). Also, these findings have some implications for the policymakers, stakeholders, and educationists of ELT.

It is imperative to add those aforementioned aspects to cater to the needs and interests of students. The current investigation also recommends the school management to have a new book or say to the least revise the book. The researcher recommends the other researchers to investigate other aspects of language, for example, pragmatics, cultural and communicative competence in the ELT textbook.

\section{References}

Aftab, A., Sheikh, A., \& William, I. (2014). An evaluation of English as a Second Language (ESL) Pakistani college textbook: Meeting the needs of the Pakistani students. International Journal of English and Literature, 5(7), 144-148.

Al-Yousef, H. (2007). An Evaluation of the New Third Grade Intermediate English Coursebook in Saudi Arabia(Unpublished Master Thesis). College of Arts, Department of English, King Saud University, Riyadh, Saudi Arabia.

Allwright, D. (1981). What do we need teaching materials for? ELT Journal, 36(1), 5-18.

Anderson, B.(2007). Pedagogical Rules and Their Relationship to Frequency in Input: Observational and Empirical Data from French. Applied Linguistics

Basturkman, H. (1999). A content analysis of ELT textbook blurbs: Reflections of the

Baghban, Z.Z. V. (2011). A Review on the Effectiveness of Using Authentic Materials in ESP courses.RELC Journal, 30, 18-38

Beale J, 2002. EFL in Japan: Whose English is it anyway? Babel, 37(2), 26-28.

Berk, R. A. (2000). Does humor in course tests reduce anxiety and improve performance? College Teaching, 48(4), 151-158.

Berry A., McNeill (Eds.), Policy and practice in language education.Hong Kong.

Byrd, P. (2001). Textbooks: Evaluation for selection and analysis for implementation. In M. CelceMurcia (Ed.).Teaching English as a second or foreign language. Boston: Heinle\&Heinle.

Brewer, E. W., \& Burgess, D. N. (2005).Professor's role in motivating students to attend class. Journal of STEM Teacher Education, 42(3),

Brumfit (eds.), Literature and the learner: methodological approaches. (pp. 1-9). Modern English Publications and the British Council.

Coffield, F., Moseley, D., Hall, E., \&Ecclestone, K. (2004). Learning styles and pedagogy in post-16 learning.A systematic and critical review. London: Learning and Skills Research Centre.

Crookes, G. \&Chaudron, C. (1991).Guidelines for classroom language teaching. In lecMurcia, M. (Ed.), Teaching English as a Second or Foreign Language. New York: Newbury

Cunningsworth, A. (1995). Choosing your coursebook. Oxford: Heinemann.

Deneire, M. (1995).Humor and foreign language teaching.Humor, 8, 285-298.

Erdem, E. (2012). Examination of the effects of a project-based learning approach on students' attitudes towards chemistry and test anxiety.World Applied Sciences Journal,17(6).764-769.

Finocchiaro, M., Brumfit, C. (1983).The functional-notional approach. Oxford: Oxford University Press.

FinocchiaroFredriksson, P., \& Olsson, R. (2006). English Textbook Evaluation: An Investigation into Criteria for Selecting English Textbooks Oxford: Oxford University Press.

Finch, A. (1999).The Task-based Classroom in Practice.TESOL Proceedings of PAC2 (The Second Pan Asia Conference) Seoul, 179- 190.

Grant, N. (1987). Making the most of your textbook. Oxford: Heinemann Publishers Ltd.

Gilbert, J. B. (2010). Pronunciation as orphan: What can be done? Speak Out, 43, 3-7.

Griffiths, B. (2011). Integrating pronunciation into classroom activities. British Council \& BBC.

Harmer, J. (2001).The practice of English language teaching. London/New York, 401-405.

Hutchinson, T. \& Torres, E. (1994). The textbook is an agent of change. ELT Journal, 48(4), 315-

HCollins, P. \& Hood, S. (1999). Grammar in current ESL textbooks: a critical appraisal.

Hutchinson, T. \& A. Waters. (1987). ESP: A learning-centered approach. CUP

Jahangard, A. (2007). Evaluation of EFL materials taught at Iranian public high schools. The Asian EFL Journal, 9(2), 130-150.

Johns, A. (1991). English for specific purposes: its history and contribution. In Celce-Murcia, M. (Ed.).Teaching English as a Second or Foreign Language (pp. 67-77). Boston, MA: Heinle\&Heinle. 
Kiyani, G. Navidiniya, H. \&Momeniyan, M. (2011). Critical Review of National Program: Revisiting the Approach of National Curriculum towards Foreign Language Education. Jesarathaye Zabani Journal, 2(6), p. 1

Karppinen, T. (2013).Reading Activities in EFL-Textbooks: An analysis of upper secondary school textbooks.

Khattak, Z. I., Jamshed, T., Ahmad, A., \& Baig, M. N. (2011). An investigation into the causes of English language learning anxiety in students at AWKUM. Procedia-Social and Behavioral Sciences, 15, 1600-1604.

Littlejohn, A. (1998). The analysis of language teaching materials: Inside the Trojan Horse.

L. E. Sheldon (Ed.). ELT course books and materials: Problems in evaluation and ELT Documents (p. 126). London: Modern English publications. British Council.

Mahmood, K., ZafarIqbal, M.,\&Saeed, M. (2009). Textbook Evaluation through Quality Indicators: The Case of Pakistan. Bulletin of Education and Research, 32(2), 1-27.

Maley, A. (1989a).Down from the pedestal: Literature as a resource.In R. Carter, R. Walker \& C.

McKay, S. L. (2000). Teaching English as an international language: Implications for cultural materials in the classroom.TESOL Journal, 9(4), 7-11. [39]

McKay, S. L. (2002). Teaching English as an international language. Oxford: Oxford University Press.

Littlewood, W. (2004). The task-based approach: some questions and suggestions. ELT Journal, 58(4), 319 - 326.

Morris, P. (1995). The Hong Kong school curriculum: development, issues, and policies. Hong Kong: Hong Kong University Press

Montasser, M. A. (2013). Developing an English language textbook evaluative checklist. IOSR Journal of Research \& Method in Education, 1(3), 55-70.

Nation, I.S.P. (2001).Learning vocabulary in other languages p 9 -21. Cambridge university press.

Nunan, D. (1999). Second language teaching and learning. Cambridge: Cambridge University Press.

Nunan, D., \& Lamb, C. (1996).The Self-Directed Teacher. Cambridge: Cambridge University Press.

Richards, J., \& Rodgers, T. (2001).Approaches and methods in language teaching.Cambridge: Cambridge University Press.

O’Neil, R.O. (1982). Why use textbooks?ELT Journal, 36(2), 104-111.

Richards, J.C. (2001). Curriculum development in language teaching. Cambridge: Cambridge University Press.

Safarnavadeh, Kh. Aliasgari, M., Mosapour, N.,\&Ananisarab.(2009). Evaluation of high school English language textbooks based on the criteria derived from the communicative approach to teaching.Journal of Curriculum Studies, 5(17), 86 - 114.

Sheldon, L. E. (1987). ELT textbooks and materials: problems in evaluation and development.ELT Documents 126. London: Modem English Publications and the British Council.

Sugiyono. 2009. MetodePenelitianKuantitatif, Kualitatif, dan R\&D. Bandun

Tomlinson, B. (Ed.). (2011). Materials development in language teaching. Cambridge University Press.

Tomlinson, B., \& Masuhara, H. (2004). Developing Language Course Materials. Singapore: SEAMEO Regional Language Centre.

Tomlinson, B. (1998). Materials development in language teaching. Cambridge: Cambridge University Press.

Vetter, R., Ward, C., \& Shapiro, S. (1995). Using color and text in multimedia Projections.IEEE Multimedia, 2(4), 46-54.

Widodo, H. P. (2015). Textbook analysis on college academic writing. TEFLON Journal, 18(2), 109122.

White, A. (2009). Evaluation of an EFL Coursebook Based on Criteria Designed by McDonough and Shaw. (Online), (http://www.pdfchaser.com/ EVALUATION-OF- EFL-COURSEBOOKBASED-ON-CRITERIA- DESIGNED-BY-MCDONOUGH-AND-SHAW.html), retrieved on January 13th, 2019.

Yulianti, R. 2011. Content Analysis on the English E-book "Developing English Competencies for Senior High School (SMA/MA) Grade X" (Unpublished Thesis). Malang: Faculty of Letters State University of Malang. 